\title{
Ozone Depletion, a Big Threat to Climate Change: What can be Done?
}

\author{
Sumera Aziz Ali ${ }^{1 *}$, Savera Aziz Ali ${ }^{2}$ and Nadir Suhail ${ }^{3}$ \\ ${ }^{1}$ Department of Community Health Sciences, Aga Khan University Hospital, Pakistan \\ ${ }^{2}$ School of Nursing and Midwifery, Aga Khan University Hospital, Pakistan \\ ${ }^{3}$ Deparment of Paediatrics and child health, Aga Khan University Hospital, Pakistan
}

Submission: January 04, 2017; Published: February 03, 2017

*Corresponding author: Sumera Aziz Ali, Department of Community Health Sciences, Aga Khan University Hospital, Karachi, Pakistan, Tel: +92 213486 4837; 03012229390; E-mail: sumera.ali@aku.edu

\begin{abstract}
Ozone in the stratosphere is very important as it acts as a safeguard for the earth and protects life from harmful ultraviolet radiations coming from the sun. Depletion of stratospheric ozone, resulting from atmospheric pollution has led to increased ultraviolet radiation at the earth's surface as well as spectral shifts to the more biologically damaging shorter wavelengths. A decrease in the concentration of stratospheric ozone enhances the solar ultraviolet (UV) radiation, which is harmful to the growth of the plant and various other metabolic processes of the organisms and might cause changes in pigment concentrations, nucleic acids, and proteins. Multiple causes of ozone depletion have been identified in the literature review, but the findings are not synthesized at one place. Thus, the purpose of this paper was to review the causes of ozone depletion and to propose the interventions to address this problem in order to avoid the climate change and its associated outcomes.
\end{abstract}

Keywords: Ozone depletion; Climate change; Interventions

\section{Introduction}

Ozone in the stratosphere is very important as it acts as a safeguard for the earth and protects life from harmful ultraviolet radiations coming from the sun [1]. About $90 \%$ of ozone is located in the stratosphere $(8-18 \mathrm{~km})$ and only $10 \%$ in the troposphere (below $8 \mathrm{~km}$ ) [1]. Stratospheric ozone depletion has been recorded from the temperate to Polar Regions [2]. Ozone in the troposphere is a greenhouse gas, trapping the long wave radiation in $9.6 \mathrm{~nm}$ bands affecting the energy budget of the earth-atmosphere system [3]. Atmospheric ozone has two types of effects on the temperature balance of the earth, it absorbs solar ultraviolet radiations, which heats the stratosphere and it also absorbs infrared radiation emitted by the earth's surface effectively trapping heat in the troposphere [4]. Therefore, the climate impact of changes in ozone concentration is important and varies with altitude (Troposphere to Stratosphere) at which these ozone changes occur [4]. Depletion of stratospheric ozone, resulting from atmospheric pollution has led to increased ultraviolet radiation at the earth's surface as well as spectral shifts to the more biologically damaging shorter wavelengths $[5,6]$.
A decrease in the concentration of stratospheric ozone enhances the solar ultraviolet (UV) radiation, which is harmful to the growth of the plant and various other metabolic processes of the organisms and might cause changes in pigments concentrations, nucleic acids and proteins [7,8]. Moreover, exposure to elevated concentrations of ozone is associated with increased hospital admissions for pneumonia, chronic obstructive pulmonary disease, asthma, allergic rhinitis, and other respiratory diseases, and with premature mortality $[9,10]$. Multiple causes of ozone depletion have been identified in the literature review, but the findings are not synthesized at one place. Thus, the purpose of this paper was to review the causes of ozone depletion and to propose the interventions to address this problem in order to avoid the climate change and its associated outcomes.

\section{Methodology}

Studies on this topic of ozone depletion were identified through the search engines including Pub med, science direct, Springer link, Cochrane library, and Google scholar Furthermore, World Health Organization (WHO) website was also used for 


\section{Global Journal of Pharmacy \& Pharmaceutical Sciences}

getting some information regarding the topic. The keywords which were used are: "ozone layer depletion", "ozone depletion and Pakistan", "global data about ozone depletion", "ozone depletion in developing countries".Around twenty articles were reviewed completely, including reports.

\section{Findings of review}

It is known that air pollution is and will be directly influenced by future changes in emissions of pollutants, climate, and stratospheric ozone, and will have significant consequences for human health and the environment [11]. UV radiation is one of the important factors for the formation of photochemical smog, which includes troposphere ozone and aerosols; it also initiates the production of hydroxyl radicals $\left({ }^{\circ} \mathrm{OH}\right)$, which control the amount of many climates- and ozone-relevant gases (e.g., methane and HCFCs) in the atmosphere [12]. Numerical models predict that future changes in UV radiation and climate will modify the trends and geographic distribution of ' $\mathrm{OH}$, thus affecting the formation of photochemical smog in many urban and regional areas [12]. Concentrations of ${ }^{\circ} \mathrm{OH}$ are predicted to decrease globally by an average of $20 \%$ by 2100 , with local concentrations varying by as much as a factor of two above and below current values. If emissions of anthropogenic air pollutants from combustion of fossil fuels, burning of biomass, and agricultural activities continue to increase, concentrations of troposphere $\mathrm{O}_{3}$ will tend to increase over the next 20-40 years in certain regions of low and middle latitudes because of interactions of emissions, chemical processes, and climate change. Climate-driven increases in temperature and humidity will also increase production of tropospheric $\mathrm{O}_{3}$ in polluted regions1 $[11,13]$.

Stratospheric ozone layer depletion has been recognized as a problem by the Vienna Convention for the protection of the ozone layer and the 1987 Montreal Protocol (MP) for quadrennial ozone assessments and monitoring of stratospheric ozone concentrations and emissions of ozone destructing substances [14]. Industrialized countries have contributed significantly to the problem by releasing chlorofluorocarbons (CFCs) and halons in the atmosphere [15]. The effect of these chemicals, which were known for their inertness, non flammability and non toxicity, was discovered in 1874 [16]. Action to deal with the effects of CFCs and halons was initiated in 1985 in a 49-nation UN meeting. 21 nations signed a protocol limiting ozone depleting substances (ODS) including CFCs and halons. An Interim Multilateral Fund under the Montreal Protocol (IMFMP) was established to provide loans to finance the costs to developing countries in meeting global environmental requirements [17]. The IMFMP is administered by the World Bank, the UN Environmental Program, and the UN Development Program [18]. As a result of these agreements, global consumption of CFCs fell by more than 70\% between 1986 and 1996 [17]. The campaign against CFC use in aerosols and packaging is often presented as an example of a massive and noble behavior and social change in populations [17]. On a global scale, if 1990 is treated as the reference period, then moderately high annual mean maximum ozone concentrations of 60 parts per billion (ppb) were anticipated in central Europe, China, Brazil, South Africa, and eastern North America during summertime.

By 2030, under a high emission cicumstances, the area experiencing a background of $60 \mathrm{ppb}$ was expected to expand significantly, especially in Europe and North America $[19,20]$. By 2060 , most of the populated continental areas would experience ozone concentrations of at least 60 ppb [21-23]. By 2100, much of the Northern hemisphere was expected to have annual mean maximum ozone levels of $60 \mathrm{ppb}$, as were most of the populated areas of the Southern Hemisphere [24]. The global average populationweighted8-hr maximum ozone concentration was likely to increase by 9.4 parts per billion per volume (ppb)with approximately 500,000 additional deaths compared with the same concentration in 2000, with the largest increases over South Asia (nearly15 ppb) and with large increases in the Middle East, Southeast Asia, Latin America, and East Asia [25,26]. By the end of the twenty-first century anthropogenic climate change alone would decrease background ozone concentrations over the United States, while ozone produced internally would increase [27].

The authors anticipated that over the eastern United States, up to 12 additional days annually would exceed $80 \mathrm{ppb}$ [28]. In England, whales and United States when the authors assumed thresholds for the health effects of ozone, the increase in health effects due to ozone was relatively small. If no threshold is assumed, then ozone is projected to increase premature deaths by 10,20 , and $40 \%$ for the years 2020,2050 , and 2080 , respectively [29]. Using a threshold of $25 \mathrm{ppb}, 191,000$ deaths worldwide could be avoided using currently enacted legislation, and 458,000 deaths could be avoided using maximum reasonable reduction technologies. On the basis of a limited number of modeling studies, climate change is likely to increase ozone concentrations in high-income countries when precursor emissions are held constant, leading to increased morbidity and mortality [30].

Increased UV-B through stratospheric ozone depletion leads to an increased chemical activity in the lower atmosphere (the troposphere) [31]. The effect of stratospheric ozone depletion on tropospheric ozone is small (but significant) as compared to the ozone generated anthropogenically in areas already experiencing air pollution. Modeling and experimental studies suggest that the impacts of stratospheric ozone depletion on tropospheric ozone are different at different altitudes and in different chemical regimes [32]. As a result, the increase in ozone due to stratospheric ozone depletion may be greater in polluted regions [33]. Attributable effects on concentrations are expected only in regions where local emissions make minor contributions. The vertical distribution of NOX $\left(\mathrm{NO}_{-} \mathrm{NO}_{2}\right)$, the emission of volatile organic compounds and the abundance of water vapor, are important influencing factors [34]. The longterm nature of stratospheric ozone depletion means that even 
a small increase in tropospheric ozone concentration can have a significant impact on human health and the environment [11].

The impact of the interaction between ozone depletion and future climate change is complex and a significant area of current research [35]. For air quality and tropospheric composition, a range of physical parameters such as temperature, cloudiness, and atmospheric transport will modify the impact of UV-B [36]. Changes in the chemical composition of the atmosphere including aerosols will also have an impact. For example, tropospheric $\mathrm{OH}$ is the 'cleaning' agent of the troposphere [31]. While increased UV-B increases the $\mathrm{OH}$ concentration, increases in the concentration of gasses like methane, carbon monoxide, and volatile organic compounds will act as sinks for $\mathrm{OH}$ in the troposphere and hence change air quality and chemical composition in the troposphere. Also, changes in the aerosol content of the atmosphere resulting from global climate change may affect ozone photolysis rate coefficients and hence reduce or increase tropospheric ozone concentrations [11].

\section{Stuation in Pakistan}

The ozone layer depletion and its harmful impact on living beings have been a greater concern of all the scientists all over the world including Pakistan [36]. The annual, monthly and seasonal analyses have been performed to check the status $[37,38]$. The variation in total column of ozone has been observed during these analyses and decrease in total column of ozone has been seen in all the investigations from 1987-2008.

\section{Annual analysis}

The annual analysis of total column ozone data has been done by generating a time series for the period 1987-2008. The time series shows that there is a sharp decline in the thickness of ozone layer particularly from 1993 onwards over Pakistan. The annual ozone anomalies have been calculated with the help of observed data. The anomalies show a decreasing trend of ozone and this loss in total column ozone give a clue that ozone layer thickness has reduced and thinness has increased during the study period. The total change observed in ozone over the last 21 years (1987-2008) is-5.67Dobson units (D.U). It is assumed that this decrease can be due to huge gaseous emissions of Carbondioxide $\left(\mathrm{CO}_{2}\right)$ and particularly Chlorofluorocarbons (CFC's) which is the main cause of ozone depletion over Pakistan.

\section{Monthly analysis}

Monthly analysis of ozone shows a lot of variations in ozone thickness throughout the year. There are months in which the ozone thickness remains far above the permissible limits of ozone (i.e. 260 D.U. in tropics near the equator) whereas, on the other hand, there are few months when the ozone layer becomes thin and the value of ozone calculated below the 260 D.U. The highest amounts of total column ozone over Pakistan occur from March-May, the amount then starts to decrease from June-September. While the lowest amount of total column ozone occurs from October-December, the amount of zone again increases from January-February. The total decrease in ozone thickness is -4.2 D.U which is statistically significant. The wind transport of ozone is principally responsible for this monthly variation of ozone patterns.

\section{Seasonal analysis}

The behavior of ozone varies from season to season. The highest level of ozone occurs in spring, not in summer and the lowest in the autumn instead of winter. In winters, the concentration of ozone remains above permissible limit, i.e., 260 D.U. The highest value of ozone in winters was in 1990 which is 292 D.U. In spring, the concentration of ozone also remains above the permissible limit of 260 D.U. The highest value of ozone in springs was in 1991 i.e., 316 D.U. The peak value of ozone in summers is 292 D.U in 1990 \& 2005.The ozone layer thinning is maximum all over the globe during autumn. The same situation can be analyzed during the autumn season in the atmosphere above Pakistan. The value of ozone reduced to a large extent and it falls below the permissible limit of 260 D.U. The lowest value of ozone in autumn is 242 D.U in 1998.The total change calculated in spring is -10.5 D.U, summer is -6.3 D.U, winter is -3.15 D.U while in autumn, it is-2.0 D.U. The wind transport is the major factor responsible for the seasonal variations of ozone patterns. The relationship between ozone depletion and solar radiation has also been seen in the same study. It is concluded that ozone and solar radiations are inversely proportional to each other. From December to April when solar radiations are less intense the ozone thickness reaches to its peak values. Whereas from May till November due to the high intensity of solar radiations the concentration of ozone minimize and its concentration during October and November reduced so much that ozone reaches to its threshold values over Pakistan [8]. It has been observed from studies on marine organisms that there is a remarkable increase in the flux of UV radiation reaching the Arabian sea through the ozone filter. It is effective particularly in Pakistan atmospheric region (PAR) that is situated in the west and northwest of South Asia. It lies from 23.45 to 36.75 in the northern latitudes, and from 61 to 75.5 eastern longitudes. Ozone depletion has also effects on marine life as shown by studies. Studies conducted on Baluchistan and Sindh costs showed that there is a negativecorrelation between the yield of fish and UV radiation, as the UV-B increases due to ozone depletion, the yield of fish decreases [5].

\section{Recommendations}

In order to address the challenges posed by climatic change and to protect the ozone layer following steps can be taken.

I. Plan and implement the national climate change policy and action plan.

II. Promote the use of ozone-friendly technologies.

III. Phase out the use of ozone-depleting substances with the provisions of Montreal protocol. 
IV. Long-term monitoring of the expected decrease in polar and global ozone loss in response to the measures taken based on the Montreal Protocol and its amendments is required. The ultimate goal is to obtain accurate information on the evolution of the ozone layer (total column) and its effect on surface, UV, together with the monitoring of columns of ozone depleting substances (ODS); CFC's and their replacement HCFCs, and halons. Specifically, information on the changes (trends) in chlorine loading is needed, both in the troposphere and in the stratosphere.

V. More detailed policy-relevant information includes the monitoring of the height distribution of ozone and ODS compounds, in addition to total column information.

VI. Continued assessment and improvement of regulatory action are needed until the recovery of the ozone layer is a fact, currently not expected to happen before 2050 .

VII. A global daily monitoring of the noontime clear-sky UV Index will also give information on the occurrence of extreme values, which are typically related to ozone depletion events.

VIII. The main public health responses to the projected health impacts of climate change are mitigation and adaptation. Adaptation is not an effective risk management strategy for poor air quality because physiologic mechanisms to decrease susceptibility to ozone and other air pollutants are limited. Evidence suggests that reducing current tropospheric ozone concentrations reduces morbidity and mortality, with significant savings in medical care costs. Additional research is needed to reduce the uncertainties associated with projections of the health impacts of changing concentrations of ozone. Research is needed to better understand the impacts of future emissions pathways, climate change impacts on concentrations of fine particles and gases, how changing weather patterns could influence the frequency and severity of episodes of poor air quality, population sensitivity, and how these factors might interact [30].

\section{Conclusion}

It seems the most important cause of Ozone depletion seems to be anthropogenic. Therefore, a lot of research needs to be done particularly in Pakistan. It is the right time to change behavior towards the environment by creating awareness among public. However, Montreal protocol activities have shown the commitments in the entire world including Pakistan. But there are so many men - made chemicals, which need to be controlled in order to overcome the problems of ozone - depletion.

\section{References}

1. Andersen SO, Halberstadt ML, Borgford-Parnell N (2013) Stratospheric ozone, global warming, and the principle of unintended consequencesAn ongoing science and policy success story. J Air Waste Manag Assoc 63(6): 607-647
2. Maione M, Giostra U, Arduini J, Furlani F, Graziosi F, et al. (2013) Ten years of continuous observations of stratospheric ozone depleting gases at Monte Cimone (Italy)-Comments on the effectiveness of the Montreal Protocol from a regional perspective. Sci total Environ 445: 155-164.

3. Box MA, Box GP (2015) Physics of Radiation and Climate: Crc Press.

4. Gore A (2013) Earth in the balance: forging a new common purpose: Routledge.

5. Seinfeld JH, Pandis SN (2012) Atmospheric chemistry and physics: from air pollution to climate change: John Wiley \& Sons.

6. Craig E, Williamson, Richard G Zepp, Robyn M Lucas, Sasha Madronich, et al. (2014) Solar ultraviolet radiation in a changing climate. Nature Climate Change 4(6): 434-441.

7. Worrest RC, Caldwell MM (2013) Stratospheric ozone reduction, solar ultraviolet radiation and plant life: Springer Science \& Business Media.

8. Bornman JF, Barnes PW, Robinson SA, Ballare CL, Flint S, et al. (2015) Solar ultraviolet radiation and ozone depletion-driven climate change: effects on terrestrial ecosystems. Photochem Photobiol Sci 14(1): 88107.

9. Vinikoor-Imler LC, Owens EO, Nichols JL, Ross M, Brown JS, et al. (2014) Evaluating potential response-modifying factors for associations between ozone and health outcomes: a weight-of-evidence approach. Environ Health Perspect 122(11): 1166-1176.

10. Kahle JJ, Neas LM, Devlin RB, Case MW, Schmitt MT, et al. (2015) Interaction Effects of Temperature and Ozone on Lung Function and Markers of Systemic Inflammation, Coagulation, and Fibrinolysis: A Crossover Study of Healthy Young Volunteers. Environ Health Perspect 123(4): 310-316.

11. Madronich S, Shao M, Wilson SR, Solomon KR, Longstreth JD, et al. (2015) Changes in air quality and tropospheric composition due to depletion of stratospheric ozone and interactions with changing climate: implications for human and environmental health. Photochem Photobiol Sci 14 (1): 149-169.

12. Kazadzis S, Amiridis V, Kouremeti N (20112) The effect of aerosol absorption in solar UV radiation. Advances in Meteorology, Climatology and Atmospheric Physics 1041-1047.

13. Tang X, Wilson S, Solomon K, Shao M, Madronich S, et al. (2011) Changes in air quality and tropospheric composition due to depletion of stratospheric ozone and interactions with climate. Photochem Photobiol Sci 10(2): 280-291.

14. Wettestad J (2002) The Vienna Convention and Montreal Protocol on ozone-layer depletion. Explaining Regime Effectiveness: Confronting Theory with Evidence. In: EL Miles, et al. (Eds.), pp. 149-70.

15. Agarwal A, Narain S (2012) 5 Global warming in an unequal world. Handbook of Climate Change and India: Development, Politics and Governance.

16. Myers RL (2007) The 100 most important chemical compounds: a reference guide: ABC-CLIO.

17. Patlis JM (1992) Multilateral Fund of the Montreal Protocol: A Prototype for Financial Mechanisms in Protecting the Global Environment. Cornell International Law Journal 25(1): 181.

18. Dessler AE, Parson EA (2003) Protecting the ozone layer: science and strategy: Oxford University Press.

19. Alford J (2010) Climate Change and Human Health Consequences. Social Sciences.

20. Dawson B, Spannagle M (2008) The complete guide to climate change: Routledge. 
21. Orru H, Andersson C, Ebi KL, Langner J, Åström C, et al. (2013) Impact of climate change on ozone-related mortality and morbidity in Europe. Eur Respir J 41(2): 285-294.

22. Gao Y, Fu JS, Drake JB, Lamarque JF, Liu Y (2013) The impact of emission and climate change on ozone in the United States under representative concentration pathways (RCPs). Atmos Chem Phys 13(18): 9607-9621.

23. Douglass AR, Newman PA, Solomon S (2014) The Antarctic ozone hole: An update.

24. Silva RA, West JJ, Lamarque J-F, Shindell DT, Collins WJ, et al. (2016) The effect of future ambient air pollution on human premature mortality to 2100 using output from the ACCMIP model ensemble. Atmos Chem Phys 2016: 9847-9862.

25. Crutzen PJ (2016) The Influence of Nitrogen Oxides on Atmospheric Ozone Content. In: Paul J Crutzen (Ed.), A Pioneer on Atmospheric Chemistry and Climate Change in the Anthropocene: Springer, pp. 108 116

26. Turner A, Fiore AM, Horowitz LW, Bauer M (2013) Summertime cyclones over the Great Lakes Storm Track from 1860-2100: variability, trends, and association with ozone pollution. Atmos Chem Phys 13(2): 565-578.

27. Elizabeth A Barnes, Arlene M Fiore, Larry W Horowitz (2016) Detection of trends in surface ozone in the presence of climate variability. Journal of Geophysical Research: Atmospheres 121(10): 6112-6129.

28. Harald E Rieder, Arlene M Fiore, Larry W Horowitz, Vaishali Nai (2015) Projecting policy-relevant metrics for high summertime ozone pollution events over the eastern United States due to climate and emission changes during the $21^{\text {st }}$ century. Journal of Geophysical Research: Atmospheres 120(2): 784-800.

29. Geels C, Andersson C, Hänninen O, Lansø AS, Schwarze PE, et al (2015) Future Premature Mortality Due to 03, Secondary Inorganic Aerosols and Primary PM in Europe-Sensitivity to Changes in Climate, Anthropogenic Emissions, Population and Building Stock. Int J Environ Res Public Health 12(3): 2837-2869.

30. Ebi KL, McGregor G (2008) Climate change, tropospheric ozone and particulate matter, and health impacts. Environ Health Perspect 116 (11): 1449-1455.
31. Erickson DJ, Sulzberger B, Zepp RG, Austin AT (2015) Effects of stratospheric ozone depletion, solar UV radiation, and climate change on biogeochemical cycling: interactions and feedbacks. Photochem \& Photobiol Sciences 14(1): 127-148.

32. Arnold S, Emmons L, Monks S, Law KS, Ridley D, et al. (2015) Biomass burning influence on high-latitude tropospheric ozone and reactive nitrogen in summer 2008: a multi-model analysis based on POLMIP simulations. Atmos Chem Phys 15: 6047-6068.

33. Jintai Lina, Da Pana, Steven J Davisb, Qiang Zhangc, Kebin He, et al. (2014) China's international trade and air pollution in the United States. Proceedings of the National Academy of Sciences of the united states of America 111(5): 1736-1741.

34.Williams J, Le Bras G, Kukui A, Ziereis H, Brenninkmeijer C (2014) The impact of the chemical production of methyl nitrate from the $\mathrm{NO}+\mathrm{CH}_{3} \mathrm{O}_{2}$ reaction on the global distributions of alkyl nitrates, nitrogen oxides and tropospheric ozone: a global modelling study. Atmospheric Chemistry and Physics 14(5): 2363-2382.

35. Martens WJ (1998)Health impacts of climate change and ozone depletion: an ecoepidemiologic modeling approach. Environ Health Perspect 1: 241-251.

36. Ayub Khan Yousuf Zai, M Rashid Kamal Ansari, Afaq Ahmed Siddiqui, Faisal Ahmed Khan Afridi (2013) Efficacy of Non-Linear Approach in the Study of Ozone Layer Depletion. Journal of Basic \& Applied Sciences 9: 587-591.

37. Bisht H, Pande B, Chandra R, Pande S (2014) Statistical study of different solar activity features with total column ozone at two hill stations of Uttarakhand. Indian Journal of Radio \& Space Physics 43:251-62.

38. Zia Ul-Haq , Salman Tariq , Asim Daud Rana, Muhammad Ali , Khalid Mahmood (2015) Satellite remote sensing of total ozone column (TOC) over Pakistan and neighbouring regions. International Journal of Remote Sensing 36(4): 1038-1054.

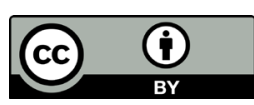

This work is licensed under Creative Commons Attribution 4.0 License DOI: 10.19080/GJPPS.2017.01.555556 